\title{
Traction-assisted endoscopic full-thickness resection for extraluminal type gastrointestinal stromal tumor
}

Endoscopic full-thickness resection (EFTR) was developed to treat upper gastrointestinal submucosal tumors (SMT) originating from the muscularis propria (MP) $[1,2]$. However, EFTR for extra-luminal type SMT is difficult because this requires intraperitoneal manipulation. $A$ clip-and-line traction method is useful for reduction of procedure time during endoscopic submucosal dissection of early gastric cancer [3] and EFTR of gastric SMT [4]. Recently, we have found that clip-and-line traction method is also useful for EFTR of extra-luminal type gastrointestinal stromal tumors (GISTs).

A woman in her 70 s underwent a chest computed tomography scan for anterior chest pain, which identified an exophytic tumor in the stomach. Esophagogastroduodenoscopy revealed an SMT in the gastric body ( $\triangleright$ Fig. 1). Echoendoscopy revealed the $24-\mathrm{mm}$ tumor connected to the muscularis propria and protruding into the peritoneal cavity ( $>$ Fig. 2). EFTR was performed under general anesthesia with a double-channel multi-bending scope (GIF-2TQ260M; Olympus Medical Co., Ltd., Tokyo, Japan) using an IT knife 2 (KD-611L; Olympus) and a Flush Knife BT-S 2.0 (DK2620J-B20S; Fujifilm Medical, Co., Ltd., Tokyo, Japan) as follows ( Video 1): 1) mucosal incision and submucosal dissection to expose the border between the tumor and the MP circumferentially around the tumor; 2) muscularis incision along the tumor margin ( Fig.3a); 3) A clip was tied with 3-0 polyester suture to the mucosa overlying the tumor ( $\mathbf{F i g . 3 b}$ ); 4) The tumor was pulled into the gastric lumen, facilitating peritoneal dissection and a remnant MP incision without pseudo-capsule injury ( Fig. 3c); and 5) purse-string closure of the gastric wall defect using multiple clips (SureClip ROCC-D-26-165-C; Micro-Tech, Nanjing, China) and endoloops (HX-400U-30; Olympus) was performed ( $\vee$ Fig.3d) [5]. The procedure took 110

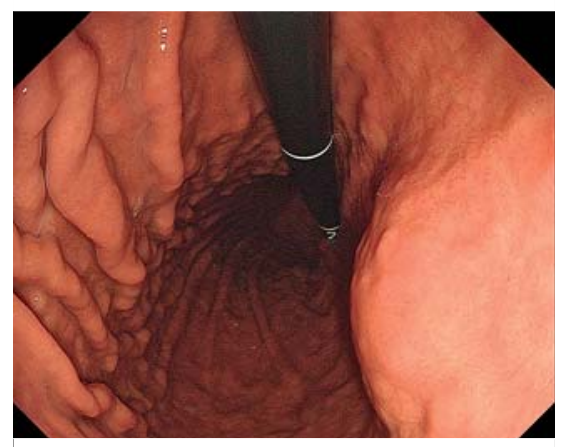

- Fig. 1 Esophagogastroduodenoscopy showing a submucosal tumor at the lesser curvature of the mid-gastric body.

min. Histological examination showed that the lesion was an intermediate-risk GIST. The patient began a liquid diet 4 days after the procedure and was discharged on day 8 .

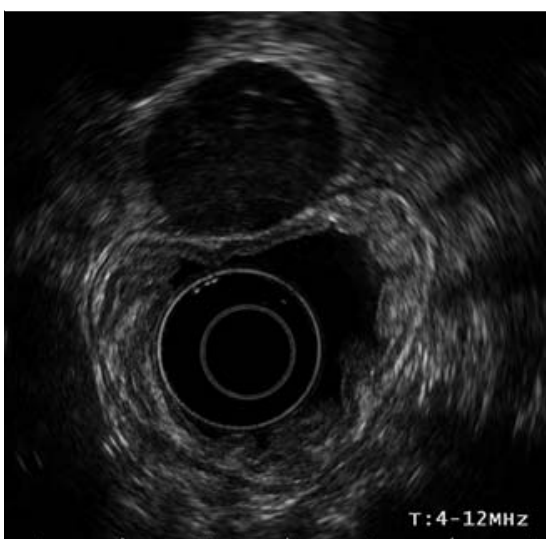

Fig. 2 Echoendoscopic image showing the exophytic low-echoic tumor measuring $24 \mathrm{~mm}$, connected to the muscularis propria.

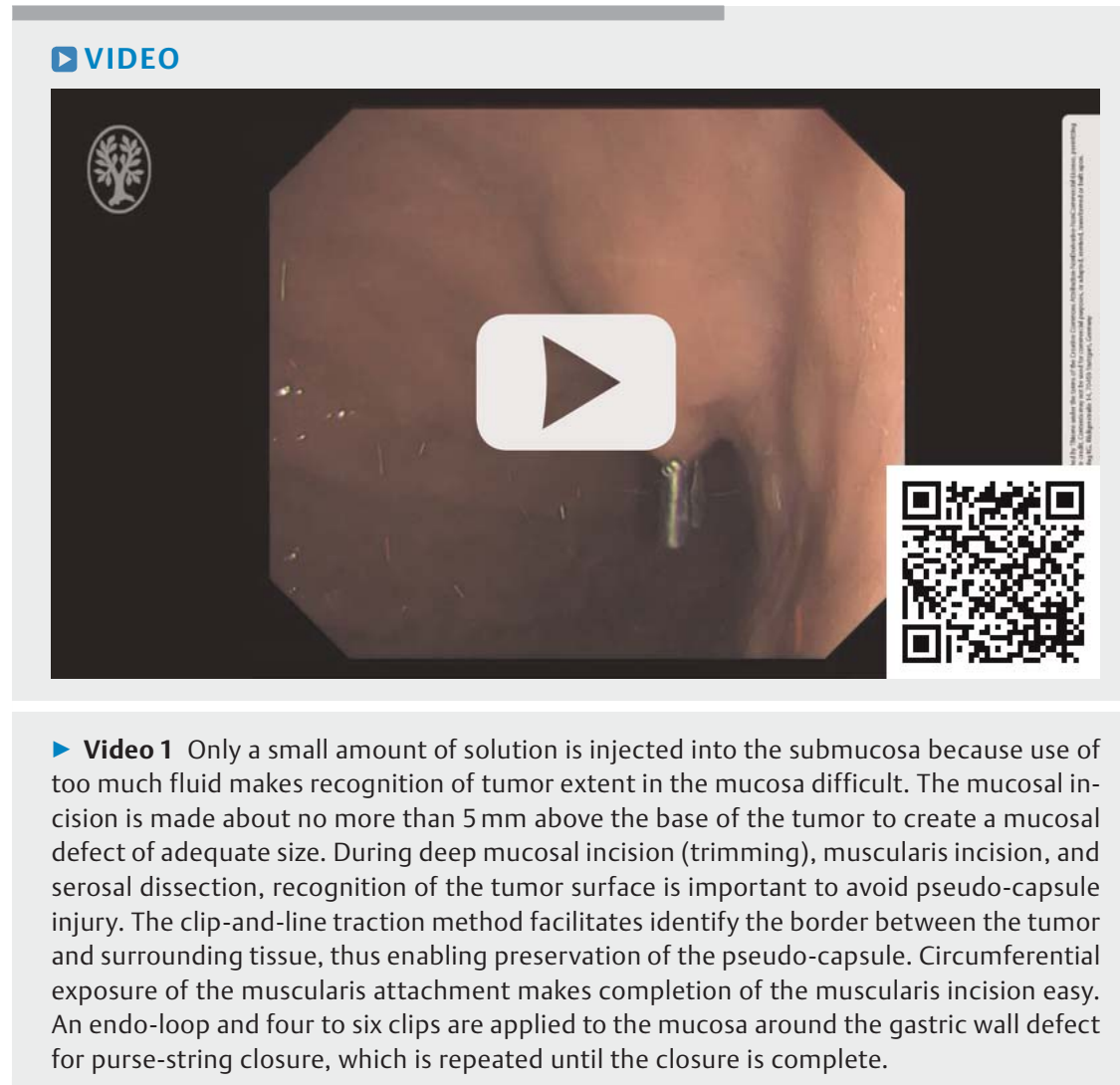



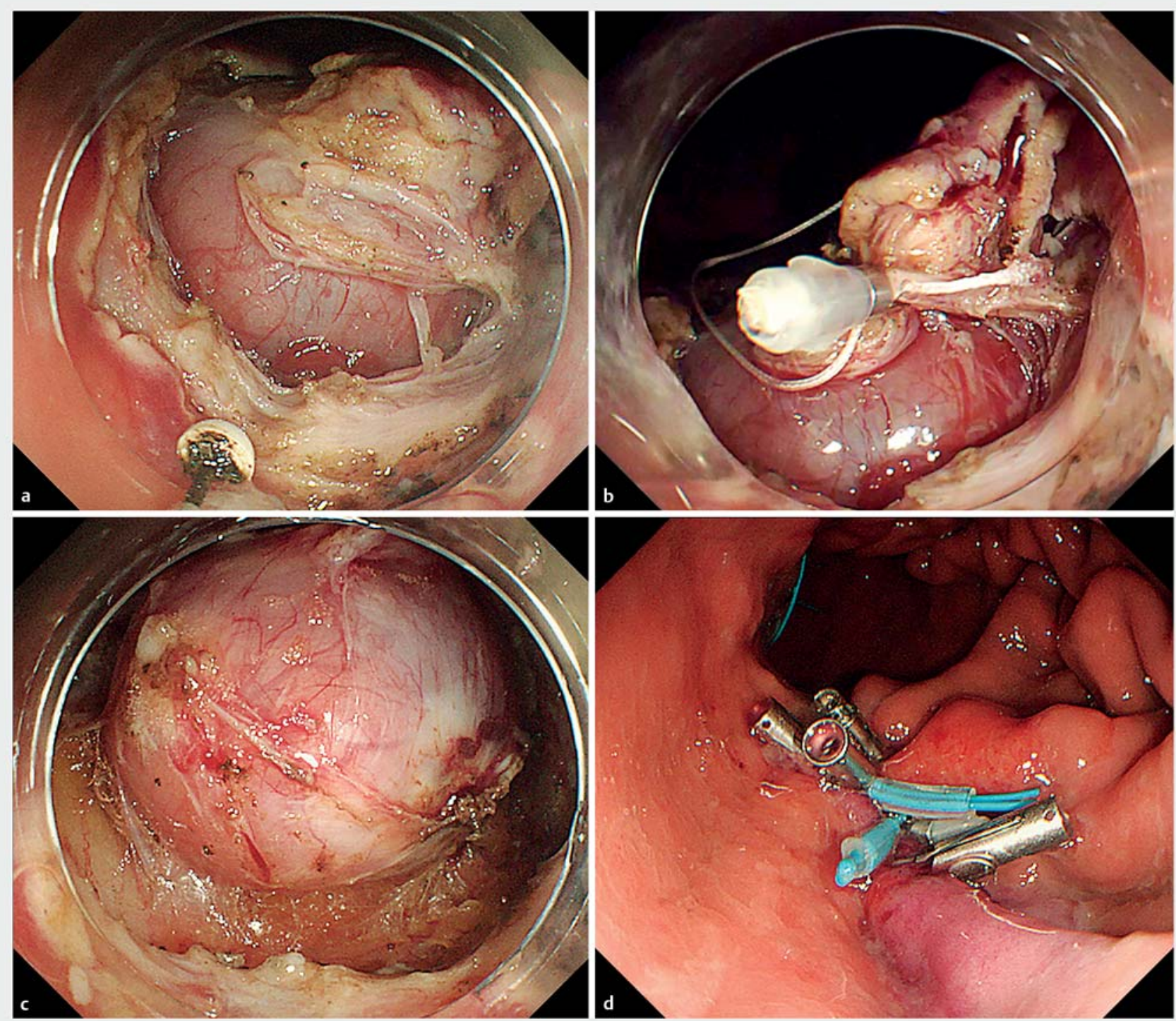

- Fig. 3 a Muscularis incision along the margin of the tumor using the IT knife 2. b Applying a clip with a suture to the mucosa overlying the lesion. c Providing traction using the clip-and-line facilitates identification and dissection of the peritoneal plane underneath the tumor. d Completing the closure as a purse-string using multiple clips and endoloops.

\section{Competing interests}

The authors declare that they have no conflict of interest.

The authors

\section{Hiromu Fukuda, Noriya Uedo, Satoki Shichijo}

Department of Gastrointestinal Oncology,

Osaka International Cancer Institute, Osaka,

Japan

\section{Corresponding author}

\section{Noriya Uedo}

Department of Gastrointestinal Oncology, Osaka International Cancer Institute, 3-1-69 Otemae, Chuo-ku, Osaka 541-8567, Japan Fax: +81-6-6945-1900 noriya.uedo@gmail.com

\section{References}

[1] Ye LP, Zhang Y, Luo DH et al. Safety of endoscopic resection for upper gastrointestinal subepithelial tumors originating from the muscularis propria layer: an analysis of 733 tumors. Am J Gastroenterol 2016; 111: 788-796

[2] Zhang Y, Peng JB, Mao XL et al. Endoscopic resection of large $(\geq 4 \mathrm{~cm})$ upper gastrointestinal subepithelial tumors originating from the muscularis propria layer: a singlecenter study of 101 cases (with video). Surg Endosc 2021; 35: 1442-1452 
[3] Yoshida M, Takizawa K, Suzuki S et al. Conventional versus traction-assisted endoscopic submucosal dissection for gastric neoplasms: a multicenter, randomized controlled trial (with video). Gastrointest Endosc 201887: 1231-1240

[4] Li B, Shi Q, Qi ZP et al. The efficacy of denta floss and a hemoclip as a traction method for the endoscopic full-thickness resection of submucosal tumors in the gastric fundus. Surg Endosc 2019; 33: 3864-3873

[5] Shi Q, Chen T, Zhong YS et al. Complete closure of large gastric defects after endoscopic full-thickness resection, using endoloop and metallic clip interrupted suture.

Endoscopy 2013; 45: 329-334

\section{Bibliography}

Endosc Int Open 2021; 09: E1243-E1245

DOI 10.1055/a-1483-9776

ISSN 2364-3722

(c) 2021. The Author(s).

This is an open access article published by Thieme under the terms of the Creative Commons Attribution-NonDerivativeNonCommercial License, permitting copying and reproduction so long as the original work is given appropriate credit. Contents may not be used for commercial purposes, or adapted, remixed, transformed or built upon. (https:// creativecommons.org/licenses/by-nc-nd/4.0/)

Georg Thieme Verlag KG, Rüdigerstraße 14, 70469 Stuttgart, Germany

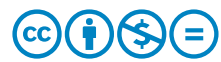

